\title{
Health Beliefs and Breast Self-Examination among Undergraduate Female Students in Public Universities in Klang Valley, Malaysia
}

\author{
Mehrnoosh Akhtari-Zavare ${ }^{1 \&}$, Muhamad Hanafiah Juni ${ }^{2 *}$, Irmi Zarina Ismail ${ }^{3 \&}$, \\ Salmiah Md Said ${ }^{2 \&}$, Latiffah A Latiff ${ }^{1,2 \&}$
}

\begin{abstract}
Background: Breast cancer is the most frequently occurring cancer in women and the most common cause of cancer death worldwide. Materials and Methods: A cross-sectional study was carried out among 792 female undergraduate students in public universities in Klang Valley, Malaysia, from January to April 2011. Data were collected using a validated questionnaire developed for this study. Results: The mean age of respondents was 21.7 \pm 1.2 years. Most of them were single $(96.8 \%)$, Malay $(91.9 \%)$ and $150(19.6 \%)$ claimed they had practiced BSE. There was a significant differences between performers and non-performers correlated to age, marital status, check breast by doctor, and being trained about BSE. Performers had lower mean scores for perceived barriers and susceptibility and higher mean score for confidence. Stepwise logistic regression analysis yielded four significant predictor variables. Conclusions: Overall our findings indicate that the practice of BSE while perceived as being important is not frequently practiced among female in Malaysia. Targeted education should be implemented to improve early detection of breast cancer.
\end{abstract}

Keywords: Breast cancer - breast self-examination - breast cancer beliefs - students - Malaysia

Asian Pac J Cancer Prev, 16 (9), 4019-4023

\section{Introduction}

Breast cancer is the most common cause of deaths and the most frequently diagnosed cancer among women worldwide (IARC, 2013). In Malaysia, there was 3,525 female breast cancer cases registered in the National Cancer Registry (NCR) for 2006, accounted for $29.9 \%$ of all cancer cases registered (National Cancer Registry, 2006).

Early detection of breast cancer is crucial for early treatment and reduction in related mortality.

Recommended screening methods to reduce breast cancer mortality and morbidity include breast selfexamination (BSE), clinical breast examination (CBE), and mammography (Ersin and Bahar, 2013; Yilmaz et al., 2013). Although, there is debate surrounding the efficacy of routine BSE in early detection of breast cancer (Giridhara et al., 2011). But, among women older than 20 years, BSE recommended as a screening method for increasing breast health awareness, because it is cheap, widely available, and does not require complex technical training (Giridhara et al., 2011).

Despite the relative benefits of BSE, its application remains low (Canbulat et al., 2008). Studies conducted among female teachers in Selangor, Malaysia, showed that only $19 \%$ of the women performed BSE on a regular basis (Parsa et al., 2011). Similar results were found among Iranian female, which showed only $26 \%$ conducting BSE practice. In a recent research, Iranian female were noted not know how to perform a BSE (Akhtari-Zavare et al., 2014).

Studies indicate that women's health beliefs and attitudes are the most important factors which influence whether or not they will get screened for breast cancer (Erbil and Bolukbas, 2014; Jirojwong and McLennan, 2003). The Health Belief Model has been used in studies as a theoretical framework to study BSE and other breast cancer detection behaviors. According to this model, women who present a higher risk for breast cancer, perceive breast cancer as a serious threat to their own health, have a low perception barrier, and who possess a high perception of the benefits will be more likely to practice BSE on a regular basis (Hajian-Tilaki and Auladi, 2012).

The emergence of breast disease and the subsequent development of cancer tend to be more aggressive in young women compared with breast cancer progression in the older population (Anders et al., 2008). Erbil and Bolukbas (2014) reported that knowledge about breast cancer and young women's practices and beliefs about 
BSE are not enough to increase their survival rates. Studies from Malaysia have reported that the percentage of older women regularly performing BSE ranged from $19 . \%$ to 36.7\% (Parsa et al., 2011; Akhtari-Zavare et al., 2013). It is believed that a higher rate of older women practice BSE because they are at higher risk for breast cancer. However, Malaysian studies have revealed that low percentages of both young and older women practice BSE (Parsa et al., 2011; Akhtari-Zavare et al., 2013). In order to increase breast health awareness among all women, education programs on this important health issue need to be offered early to young women.

The aim of this study was to determine the health beliefs and socio-demographic variables influencing BSE practice in a sample of Malaysian undergraduate female students, which may help to identify strategies for implementing a BSE teaching program and provide information to healthcare professionals who are working to enhance breast health.

\section{Materials and Methods}

\section{Design and sample}

A cross-sectional study was carried out among female undergraduate students in public universities in Klang Valley, Malaysia, from January to April 2011. A multistage random sampling was used to select the respondents. First, four public universities out of the six public universities in Klang Valley were selected randomly. Secondly, one faculty was selected from each of these four public universities by simple random sampling. Finally, 820 students were randomly selected from the list of the students in the selected faculty by using simple random sampling. In all 792 (96\%) undergraduate students agreed to participate and gave informed consent. Participants had to be at least 20 years old and could not have breast cancer, be pregnant, or be breast-feeding at the time of enrollment. This study obtained approval from the Ministry of Education Malaysia and Ethics Committee of the Faculty of Medicine and Health Sciences, Universiti Putra Malaysia.

\section{Instrument}

A validated and reliable self-administered, structured questionnaire was used for data collection. The questionnaire consists of two part: the first parts of questionnaire designed to obtain the information about their socio-demographic information (i.e., age, marital status, race, ethnicity and income level) and breast cancerrelated variables (i.e., family history of breast cancer, education about breast cancer and BSE, and sources of breast cancer information). This part of questionnaire was developed by the authors based on an extensive review of the literature.

The second part of questionnaire included Champion's Revised Health Belief Model Scale (CHBMS) (Champion, 1993). Only six subscales of the CHBMS that were related to BSE were used in the current study (41 items total): susceptibility to breast cancer (5 items), seriousness of breast cancer ( 7 items), benefits of breast self-examination (6 items), barriers to breast self-examination (6 items), confidence in breast self-examination (10 items), and health motivation that being concerned about health in general ( 7 items). For each item, participants were asked to rate their level of agreement using a five-point Likert scale from one (strongly disagree) to five (strongly agree). The internal consistency reliability of the instrument was assessed using Cronbach's alpha, which ranged from 0.70.9 . In addition, the question "How often do you practice breast self-examination?" was asked to determine the frequency of BSE practice, with the response options of "never," "occasionally," or "regularly (every month)." Data collection averaged 20-30 minutes per participant.

\section{Data Analysis}

Data was analyzed by using PASW Statistics 19.0 program. Normality tests were done and all of the quantitative data were found to be normally distributed. Descriptive analysis in terms of percentages, means, and standard deviations was conducted initially. Participants were divided into two groups: performers (i.e., those who performed BSE) and nonperformers (i.e., those who had never performed BSE). The independent sample t-test was used to determine whether a relationship existed between health beliefs and BSE performance. The chisquare test was used to determine whether a relationship was presented between socio-demographic and breast cancer-related variables and BSE performance. Logistic regression analysis with stepwise entry was used to examine the relationship between BSE performance and health beliefs and socio-demographic and breast cancerrelated variables.

\section{Results}

The mean age of participants was $21.7(\mathrm{SD}=1.20)$ and the average monthly income was about RM4722.7

Table 1. Responses to Champion's Health Belief Model Subscales $(\mathbf{n}=792)$

\begin{tabular}{lcrrrrr}
\hline Subscale & \multicolumn{2}{c}{ Disagree } & \multicolumn{2}{c}{ Unsure } & \multicolumn{2}{c}{ Agree } \\
& Freq. & $\%$ & \multicolumn{1}{c}{ Freq. } & $\%$ & Freq. & $\%$ \\
\hline Susceptibility & 690 & 87.1 & 87 & 11.0 & 15 & 1.9 \\
Seriousness & 249 & 31.4 & 383 & 48.4 & 160 & 20.2 \\
Benefits of BSE & 127 & 16.0 & 368 & 46.5 & 297 & 37.5 \\
Barriers of BSE & 121 & 15.3 & 492 & 58.3 & 209 & 26.4 \\
Confidence & 428 & 54.0 & 318 & 40.2 & 46 & 5.8 \\
Health motivation & 65 & 8.2 & 409 & 51.6 & 318 & 40.2 \\
\hline
\end{tabular}

Table 2. Differences in Health Beliefs between Breast Self-Examination Nonperformers and Performers $(n=792)$

\begin{tabular}{lccrc}
\hline & $\begin{array}{c}\text { Performing } \\
\text { BSE } \\
(\mathrm{n}=155) \\
\text { Mean(SD) }\end{array}$ & $\begin{array}{c}\text { Not performing } \\
\text { BSE } \\
(\mathrm{n}=637)\end{array}$ & $\mathrm{T}$ & $\mathrm{p}$ \\
\hline Susceptibility to BC & $8.8(3.2)$ & $10.1(3.7)$ & 3.7 & $0.0^{*}$ \\
Seriousness BC & $19.8(4.4)$ & $19.6(4.5)$ & -0.5 & 0.5 \\
Benefits of BSE & $21.7(4.0)$ & $21.6(4.5)$ & 0.2 & 0.8 \\
Barriers of BSE & $15.4(3.8)$ & $16.7(4.0)$ & 3.6 & $0.0^{*}$ \\
Confidence BSE & $31.5(6.5)$ & $28.1(6.9)$ & 5.5 & $0.0^{*}$ \\
Health motivation & $26.8(4.0)$ & $26.3(4.4)$ & 1.3 & 0.1 \\
\hline *Significant at level p<0.05 & & &
\end{tabular}


Table 3. Bivariate Relationships between Variables and Performing Breast Self-Examination ( $n=792)$

\begin{tabular}{|c|c|c|c|c|c|c|c|}
\hline & & \multicolumn{2}{|c|}{$\begin{array}{l}\text { Performing BSE } \\
(\mathrm{n}=155)\end{array}$} & \multicolumn{2}{|c|}{$\begin{array}{l}\text { Not performing BSE } \\
\qquad(\mathrm{n}=637)\end{array}$} & \multirow[t]{2}{*}{ T-value } & \multirow[t]{2}{*}{ p-value } \\
\hline & & $\mathrm{N}$ & $\%$ & $\mathrm{~N}$ & $\%$ & & \\
\hline Age (year) & Mean \pm SD & \multicolumn{2}{|c|}{$22.1 \pm 1.1$} & \multicolumn{2}{|c|}{$21.6 \pm 1.1$} & $\mathrm{t}=-4.6$ & $0.0^{*}$ \\
\hline \multirow[t]{2}{*}{ Ethnicity } & Malay & 138 & 19.0 & 590 & 81.0 & \multirow[t]{2}{*}{$\chi 2=2.1$} & \multirow[t]{2}{*}{0.1} \\
\hline & Non-Malay & 17 & 26.6 & 47 & 73.4 & & \\
\hline \multirow[t]{2}{*}{ Religious } & Islam & 150 & 20.0 & 599 & 80.0 & \multirow[t]{2}{*}{$\chi^{2}=1.8$} & \multirow[t]{2}{*}{0.1} \\
\hline & Non-Islam & 5 & 11.6 & 38 & 88.4 & & \\
\hline \multirow[t]{2}{*}{ Marital status } & Married & 9 & 36.0 & 16 & 64.0 & \multirow[t]{2}{*}{$\chi^{2}=4.4$} & \multirow[t]{2}{*}{$0.0 *$} \\
\hline & Single & 146 & 19.0 & 621 & 81.0 & & \\
\hline Family income(RM) & Mean $\pm \mathrm{SD}$ & \multicolumn{2}{|c|}{$4468.3 \pm 2026.2$} & \multicolumn{2}{|c|}{$4784.6 \pm 2147.4$} & $\mathrm{t}=1.6$ & 0 \\
\hline \multirow{2}{*}{ History of breast cancer in family } & Yes & 30 & 23.1 & 100 & 76.9 & \multirow{2}{*}{$\chi^{2}=1.2$} & \multirow[t]{2}{*}{0.2} \\
\hline & No & 125 & 18.9 & 537 & 81.1 & & \\
\hline \multirow[t]{2}{*}{ Checked your breast by a doctor } & Yes & 14 & 35.0 & 26 & 65.0 & \multirow[t]{2}{*}{$\chi^{2}=6.3$} & \multirow[t]{2}{*}{$0.0^{*}$} \\
\hline & No & 141 & 18.8 & 611 & 81.2 & & \\
\hline \multirow[t]{2}{*}{ Doctor trained you to perform BSE } & Yes & 57 & 30.2 & 132 & 69.8 & \multirow[t]{2}{*}{$\chi^{2}=17.6$} & \multirow[t]{2}{*}{$0.0^{*}$} \\
\hline & No & 98 & 16.3 & 505 & 83.7 & & \\
\hline
\end{tabular}

Table 4. Logistic Regression Analysis of Variables for Performing Breast Self-Examination $(\mathbf{n}=792)$

\begin{tabular}{|c|c|c|c|c|c|c|}
\hline Variables & B & SE & Wald & $\mathrm{p}$-value & OR & $95 \% \mathrm{CI}$ \\
\hline Age (year) & 0.2 & 0.0 & 13.6 & $0.0 *$ & 1.3 & $1.1-1.5$ \\
\hline Marital status & -0.4 & 0.4 & 1.0 & 0.3 & 0.6 & $0.2-1.5$ \\
\hline $\begin{array}{l}\text { Checked your breast } \\
\text { by a doctor }\end{array}$ & -0.5 & 0.3 & 2.2 & 0.1 & 0.5 & $0.2-1.1$ \\
\hline $\begin{array}{l}\text { Doctor trained you to } \\
\text { perform BSE }\end{array}$ & -0.5 & 0.2 & 7.6 & $0.0 *$ & 0.5 & $0.3-0.8$ \\
\hline Susceptibility to BC & 0.0 & 0.0 & 2.7 & 0.0 & 1.0 & $0.9-1.0$ \\
\hline Barriers of BSE & -0.0 & 0.0 & 11.7 & $0.0^{*}$ & 0.9 & $0.8-0.9$ \\
\hline Confidence BSE & 0.0 & 0.0 & 14.8 & $0.0^{*}$ & 1.0 & $1.0-1.0$ \\
\hline Constant & -7.7 & 1.9 & 15.4 & 0.0 & 0.0 & - \\
\hline
\end{tabular}

*B: Coefficient; OR: Odds Ratio; CI: Confidence Interval, *Significant at level $\mathrm{p}<0.05$

( $\mathrm{SD}=2126.7)$. The majority of the participants $728(91.9 \%)$ was Malay, Muslims749 (94.6\%) and single 767 (96.8\%). Approximately $24 \%$ of the participants trained by doctor for doing BSE, and $1.1 \%$ indicated a personal history of breast disease. A family history of breast cancer was reported by $16.5 \%$ of the participants.

The percentage of participants who performed BSE was $19.6 \%$ while the percentage of female who not performed BSE was $80.4 \%$. Among those who practice BSE, most of them practice BSE occasionally $(82,52.9 \%)$.

Among the respondents, 788 (99.5\%) of them had heard or read about breast cancer and the most popular sources was mass media (e.g., television and radio programs) $300(38 \%$ ), followed by printed materials (e.g., newspapers, brochure) $200(25.3 \%)$, doctors 130 (16.5\%), and family and friends $90(11.4 \%)$ and Internet $78(9.9 \%)$.

\section{Health Beliefs}

Response percentages to items on the six belief scales are summarized in Table 1. Eighty-seven percent of the sample did not believe they were susceptible to breast cancer and $11 \%$ were not sure. Thirty-one percent did not believe breast cancer was a serious illness. Thirty-seven percent of the participants recognized the benefits of BSE, but only $5.8 \%$ reported being confident in their ability to perform BSE correctly. Twenty-six percent of the sample believed that barriers prevented them from examining themselves, and $8.2 \%$ were not motivated to perform BSE. The barriers for not performing BSE were, "Doing BSE will be unpleasant" 341(43\%), "Doing BSE will take too much time" 94 (11.9\%), "BSE will be embarrassing to me" 310 (39.2\%), "Doing BSE during the next year will make me worry about breast cancer" 207 (26.2\%), "I don't have enough privacy to do BSE" $170(21.5 \%)$, and "I feel funny doing BSE" 254(32.1\%).

\section{Comparison of performers and nonperformers}

Comparison analyses of performers and nonperformers on health beliefs were conducted using independentsample $\mathrm{t}$ tests. Performers had lower mean scores for perceived barriers of $\mathrm{BSE}(\mathrm{t}=3.6, \mathrm{p}=0.0)$ and susceptibility to $\mathrm{BC}(\mathrm{t}=3.7, \mathrm{p}=0.0)$ and higher mean score for confidence $(\mathrm{t}=5.5, \mathrm{p}=0.0)$. No significant differences between the two groups were recorded on the seriousness, benefit, and health motivation subscales ( $>>0.05)$ (see Table 2).

Table 3 provides a comparison of performers and nonperformers on socio-demographic and breast cancerrelated variables. Significant association were identified between performing BSE and age, marital status, check breast by doctor and were educated about BSE by doctor $(p<0.05)$ were more often performers than nonperformers. No association was found between ethnicity, religious, family income, family history of breast cancer and performing BSE.

Logistic regression analysis was used to test multivariate relationships among variables that were significant in bivariate analysis. Health beliefs and sociodemographic and breast cancer-related variables were entered independently into the logistic regression analysis to identify predictors of BSE practice, which resulted in three variables with significant odds ratios ([ORs], see Table 4). Participants were less likely to perform BSE if they did not educated about BSE by doctor $(\mathrm{OR}=0.5$, $95 \% \mathrm{CI}=0.3-0.8)$, and those perceived greater barriers of BSE $(\mathrm{OR}=0.9,95 \% \mathrm{CI}=0.8-0.9)$. On the other hand, participants were more likely to perform BSE if they were confident about performing $\mathrm{BSE}(\mathrm{OR}=1.0,95 \%$ $\mathrm{CI}=1.0-1.0)$. The Nagelkerke $\mathrm{R} 2$ revealed that about $14 \%$ of the variation in the BSE practice was explained by this logistic model. 


\section{Discussion}

This study was conducted in order to examine the belief and of BSE practice among female undergraduate students in Malaysia. The $99.5 \%$ of female university students who had ever heard about $\mathrm{BC}$ is similar with the finding reported in Universiti Putra Malaysia (AkhtariZavare et al., 2013), and in Management and Science University, Shah Alam, Malaysia (Redhwan et al., 2011). In this study (19.6\%) of respondents performed BSE and among those who practice BSE, most of them practice BSE occasionally $(82,52.9 \%)$. These findings are support by Akhtari-Zavare et al. (2014) that reported $97 \%$ of the participants heard about BSE, only $(100,26 \%)$ stated that they performed BSE and among those who practice BSE, most of them practice BSE occasionally $(53,13.8 \%)$. Similarly, in a study from Turkey reported less than half of the respondents participated BSE and a few are doing BSE regularly (Andsoy and Gul, 2014). This poor practice may be due to young women's perception that they are healthy and thus do not need to perform a BSE.

Most women did not believe that they were susceptible to breast cancer, and only twenty percent agreed that breast cancer is a serious illness. The majority of participants reported that barriers to (e.g., unpleasant, embarrassing, funny) and benefits of (e.g., finding lumps early, decreasing chances of requiring surgery) performing BSE existed. Several studies have found that knowledge of breast cancer and BSE was associated with BSE practice (Karadag et al., 2014; Al-Sharbatti et al, 2013; Redhwan et al, 2011). Almost two-thirds of the women reported that they did not know about breast cancer, which correlated with low BSE performance. Thus, barriers as well as lack of knowledge about breast cancer and BSE may account for the low rate of monthly performance.

Significant differences between performers and nonperformers were identified with respect to susceptibility, barriers and confidence variables; non performers scored higher on susceptibility and barriers and lower scored on confidence variables. This could be attributable to insufficient education with respect to BSE practice and breast cancer among young women. This finding was supported by Yucel et al. (2014) a significant relationship was observed between BSE performance and the perceived barriers and confidence among respondents. The HBM presumes that women who believe they have few barriers to BSE are more likely to perform BSE (Champion, 1993), which is consistent with the result of this study. However, this result is in contrast to what was reported in a study among Turkish women regarding perceived benefits; this study concluded that women who perceived more benefits in relation breast self examination, were more likely to engage in the behavior (Erbil et al., 2014). In the current study, nearly a third of participants believed breast cancer was a serious disease; however, the lack of a significant relationship between perceived seriousness and performing BSE was consistent with the pervious study (Nahcivan and Secginli, 2007). This study showed that motivation was not a significant determinant of BSE practice. In contrast, research by Yucel et al.
(2014), indicated that a significant relationship between BSE practice and motivation exist. A possible reason for low compliance is the belief among the female students that they were not at risk for breast cancer.

Variables such as age, marital status, checked their breast by a doctor and trained BSE by doctor were shown to be significant factors in the BSE practices, and these are in agreement with studies from Malaysia (Al-Dubai et al., 2012), Iran (Naghibi et al., 2013).

The study showed that media (magazine and television) were the main sources of information about breast cancer and breast self-examination practice. These findings of other studies (Redhwan et al., 2011; AkhtariZavare et al., 2014), suggesting that media is an important source of breast cancer information for women. Another similar study reported that the most of the respondents $(92.2 \%)$ received the information from mass media (e.g. television, radio, newspaper and magazine), followed by health promotion activities $(73.8 \%)$, book $(69.6 \%)$ internet (66.9\%), and friends (64.8\%) (Nor Afiah et al., 2011).

The results of logistic regression analysis revealed that confidence in the ability to perform BSE, barrier to do BSE, age and trained BSE by doctor were significant predictors for BSE performance. Similar to other studies in the Turkey, Iran (Nahcivan et al., 2007; Tavafian et al., 2009) women who were confident in their ability to perform BSE were more likely to examine their breasts; however, most women disagreed with the high confidence items, such as "to know how to perform BSE," "feeling confident to perform BSE correctly," which indicates that women should be encouraged to perform BSE and educated about the correct method of performing BSE and its potential to detect even small changes in breasts, as supported by teh findings published by Nahcivan et al. (2007).

There are some limitations in our research. Firstly, the findings could not be generalized beyond the study sample because it focused on young educated women. Secondly, all data were self-reported with no objective measures to evaluate the women. However, the results of this study provide some understanding on BSE practices among undergraduate female students in Malaysia.

In conclusion, beliefs about confidence and perceived barriers and susceptibility to breast cancer are areas of particular significance in attempts to increase BSE practice. Also, socio-demographic can be a source of valuable information. By using the HBM constructs, health professional can gain an understanding of health beliefs that influence women's BSE practice. The information then can provide a basis for individualized intervention designed to foster women's motivation to practice BSE.

\section{Acknowledgements}

This study was supported by the Graduate Research Fellowship from University Putra Malaysia. Researchers would like to thank all the students who took part in the study and gratefully acknowledge the management officer and staff of Faculty of Medicine and Health Science, University Putra Malaysia that involved in this study. 
Health Beliefs and Breast Self-Examination among Undergraduate Female Students in Public Universities in Malaysia

\section{References}

Akhtari-Zavare M, Ghanbari-Baghestan A, Latiffah AL, et al (2014). Knowledge of breast cancer and breast selfexamination practice among Iranian women in Hamadan, Iran. Asian Pac J Cancer Prev, 15, 6531-4.

Akhtari-Zavare M, Muhamad HJ, Salmiah MS, Irmi AM (2013). Beliefs and behavior of Malaysia undergraduate female students in a public university toward breast self examination practice. Asian Pac J Cancer Prev, 14, 57-61.

Al-Dubai SAR, Ganasegeran K, Alabsi AM, et al (2012). Exploration of barriers to breast-self examination amongurban women in shah alam, malaysia: a cross sectionalstudy. Asian Pac J Cancer Prev, 13, 1627-32.

Al-Sharbatti SS, Shaikh RB, Mathew E, Al-Biate MAS (2013). Breast self examination practice and breast cancer risk perception among female university students in Ajman. Asian Pac J Cancer Prev, 14, 4919-23.

Anders CK, Hsu DS, Broadwater G, et al (2008). Young age at diagnosis correlates with worse prognosis and defines a subset of breast cancers with shared patterns of gene expression. J Clin Oncol, 26, 3324-30.

Andsoy I, Gul A (2014). Breast, cervix and colorectal cancer knowledge among nurses in Turkey. Asian Pac J Cancer Prev, 15, 2267-72.

Canbulat N, Uzun O (2008). Health beliefs and breast cancer screening behaviors among female health workers in Turkey. Eur J Oncol Nurs, 12, 148-56.

Champion, V.L. (1993). Instrument refi nement for breast cancer screening behaviors. Nursing Research, 42, 139-43.

Erbil N, Bolukbas N (2014). health beliefs and breast selfexamination among femaleuniversity nursing students in Turkey. Asian Pac J Cancer Prev, 15, 6525-9.

Ersin F, Bahar Z (2013). Barriers and facilitating factors perceived in Turkish women's behaviors towards early cervical cancer detection: A qualitative approach. Asian Pac J Cancer Prev, 14, 4977-82.

Giridhara RB, Goleen S, Sharon PC, et al (2011). Breast cancer screening among females in iran and recommendations for improved practice: a review. Asian Pac J Cancer Prev, 12, 1647-55.

Hajian-Tilaki K, Auladi S (2012). Health belief model and practice of breast self-examination and breast cancer screening in Iranian women. Breast cancer, 1-6.

International Agency for Research on Cancer (IARC)(2013). Latest world cancer statistics. Global cancer burden rises to 14.1 million new cases in 2012: Marked increase in breast cancers must be addressed. World Health Organisation

Jirojwong S, MacLennan R (2003). Health beliefs, perceived self-efficacy,and breast self-examination among Thai migrants in Brisbane. J Adv Nurs, 41, 241-9.

Karadag G, Gungormus Z, Surucu R, Savas E, Bicer F (2014). Awareness and practices regarding breast and cervical cancer among turkish women in Gazientep. Asian Pac J Cancer Prev, 15, 1093-8.

Naghibi A, Shojaeezade D, Montazeri A, yazdani J (2013). Early detection of Breast Cancer among women in Mazandaran, Iran. Iranian J Health Sci, 1, 44-9.

Nahcivan NO, and Secginli S (2007). Health beliefs related to breast self-examination in a sample of turkish women. Oncol Nurs Forum, 34, 425-32.

National Cancer Registry, Malaysia (2006). Malaysian cancer statistics, data and figure peninsular Malaysia. Ministry of Health Malaysia.

Nor Afiah MZ, Hejar AR, Looi YK, et al (2011). Breast cancer screening: How knowledgeable are female staff of a public university? IMJM, 10, 23-30.
Parsa P, Kandiah M, Parsa N (2011). Factors associated with breast self-examination among Malaysian women teachers. Eastern Mediterranean Hlth J, 17, 509-16.

Redhwan AA, Dhekra HA, Yuri V BB, et al (2011). Practice and barriers toward breast self-examination among young Malaysian women. Asian Pac J Cancer Prev, 12, 1173-8.

Tavafian SS, Hasani L, Aghamolaei T, et al (2009). Prediction of breast self-examination in a sample of Iranian women:an application of the Health Belief Model. BMC Women's Health, 9, 37.

Yilmaz D, Bebis H, Ortabag T (2013). Determining the awareness of and compliance with breast cancer screening among Turkish residential women. Asian Pac J Cancer Prev, 14, 3281-8.

Yucel SC, Orgun F, Tokem Y, Avdal EU, Demir M (2014). Determining the factors that affect breast cancer and self breast examination beliefs of turkish nurses in academia. Asian Pac J Cancer Prev, 15, 1275-80. 